\title{
Association between Attitude towards Wife Beating and Childhood Diarrhea: A Demographic and Health Survey-Based Study in 25 Sub-Saharan African Countries
}

\author{
Betregiorgis Zegeye ${ }^{D},{ }^{1}$ Mpho Keetile ${ }^{(D)},{ }^{2}$ Bright Opoku Ahinkorah $\left(\mathbb{D},{ }^{3}\right.$ \\ Edward Kwabena Ameyaw $\left(\mathbb{0},{ }^{3}\right.$ Abdul-Aziz Seidu $\left({ }^{\circ},{ }^{4}\right.$ and Sanni Yaya $\oplus^{5}$ \\ ${ }^{1}$ Shewarobit Field Office, HaSET Maternal and Child Health Research Program, Addis Ababa, Ethiopia \\ ${ }^{2}$ Department of Population Studies, University of Botswana, Private Bag 00705, Gaborone, Botswana \\ ${ }^{3}$ The Australian Centre for Public and Population Health Research (ACPPHR), Faculty of Health, \\ University of Technology Sydney, Ultimo, Australia \\ ${ }^{4}$ Department of Population and Health, University of Cape Coast, Cape Coast, Ghana \\ ${ }^{5}$ University of Parakou, Faculty of Medicine, Parakou, Benin \\ Correspondence should be addressed to Sanni Yaya; sanni.yaya@gmail.com
}

Received 7 May 2021; Accepted 26 October 2021; Published 13 November 2021

Academic Editor: Jose Guilherme Cecatti

Copyright (c) 2021 Betregiorgis Zegeye et al. This is an open access article distributed under the Creative Commons Attribution License, which permits unrestricted use, distribution, and reproduction in any medium, provided the original work is properly cited.

Background. Childhood diarrhea remains a major public health problem in sub-Saharan Africa (SSA). Women empowerment reduces child mortality, and wife beating attitude is one of the indicators of women empowerment. There is a dearth of evidence about wife beating attitudes and childhood diarrhea in SSA. Therefore, the present study aimed to examine the association between attitude towards wife beating and diarrhea among under-five children. Methods. We used Demographic and Health Surveys from 25 countries in SSA that were conducted between 2010 and 2020. Using Stata version 14 software, we carried out the analysis on 153,864 children under five. Bivariate and multivariate logistic regression analyses were applied, and the results were presented using adjusted odd ratios (aOR) at 95\% confidence interval (CI). Results. The pooled results show that $71.4 \%$ of married women disagreed with wife beating. About $20.5 \%$ of under-five children of married women had diarrhea. Childhood diarrhea varied from highest prevalence in Chad (27.9\%) to the lowest prevalence in SierraLeone $(8.5 \%)$. The study showed lower odds of diarrhea among children of married women who disagreed with wife beating $(\mathrm{aOR}=0.6695 \% \mathrm{CI} ; 0.54-0.80)$ compared to children of married women who agreed with wife beating. Moreover, the study results show that women's age $(35-39$ years-aOR $=0.48,95 \% \mathrm{CI} ; 0.31-0.74,40-44$ years-aOR $=0.57,95 \% \mathrm{CI} ; 0.35-0.93$, 45-49 years-aOR $=0.35,95 \% \mathrm{CI} ; 0.16-0.79$ ) was negatively associated with childhood diarrhea, while husband's education (primary school-aOR $=1.36,95 \% \mathrm{CI} ; 1.05-1.77$ ), parity (ever born 3-4 children-aOR $=1.36,95 \% \mathrm{CI}$; $1.09-1.70$, and $5+$ children-aOR $=1.56,95 \% \mathrm{CI} ; 1.14-2.12$ ), and religion (Muslim-aOR $=3.56,95 \% \mathrm{CI} ; 1.44-8.83$ ) were positively associated with diarrhea among under-five children. Conclusions. The study shows association between women attitude towards wife beating and childhood diarrhea. Therefore, empowering women, especially young women by increasing awareness about domestic violence, their rights, and empowering them through education and economic advancement need to be considered in order to reduce childhood diarrhea. Moreover, fertility control or birth spacing and working closely with religious leaders are important factors to consider in reducing childhood diarrhea. 
TABle 1: Year of survey and weighted sample in each studied country.

\begin{tabular}{lcc}
\hline Country & Year of survey & Weighted sample \\
\hline Angola & $2015 / 16$ & 6,167 \\
Benin & $2017 / 18$ & 7,979 \\
Burkina Faso & 2010 & 9,450 \\
Burundi & $2016 / 17$ & 7,385 \\
Cameroon & $2018 / 19$ & 4,798 \\
Chad & $2014 / 15$ & 9,726 \\
Comoros & 2012 & 1,825 \\
Congo Democratic Republic & $2013 / 14$ & 9,107 \\
Cote devoir & $2011 / 12$ & 4,244 \\
Ethiopia & 2016 & 6,417 \\
Gabon & 2012 & 2,767 \\
Gambia & 2013 & 4,860 \\
Ghana & 2014 & 3,542 \\
Guinea & 2018 & 4,823 \\
Kenya & 2014 & 12,007 \\
Liberia & $2019 / 20$ & 2,815 \\
Malawi & $2015 / 16$ & 10,758 \\
Mali & 2018 & 5,809 \\
Rwanda & $2014 / 15$ & 4,640 \\
Senegal & $2010 / 11$ & 7,255 \\
Sierra-Leone & 2019 & 5,724 \\
Togo & $2013 / 14$ & 4,387 \\
Uganda & 2016 & 8,123 \\
Zambia & $2018 / 19$ & 5,335 \\
Zimbabwe & 2015 & 3,921 \\
Total & & 153,864 \\
\hline
\end{tabular}

\section{Introduction}

Globally, substantial progress has been made in reducing death among children under five [1,2], from 12.6 million in 1990 to 5.2 million in 2019 [1]. As of 2019, approximately 5.2 million under-five children died from preventable and treatable causes globally [1]. Sub-Saharan Africa (SSA) and Central and Southern Asia accounted for more than $80 \%$ of the 5.2 million under-five deaths in 2019 , and jointly they account for $52 \%$ of the global under-five child mortality. SSA remains the region with the highest under-five mortality [2], with 1 child in 13 dying before his or her fifth birthday [1]. Diarrhea is the leading killer of children, and it accounted for approximately $8 \%$ of all deaths of under-five children in 2017.

Women empowerment is one of the mechanisms that can be used to improve child's health and reduce under-five mortality [3,4]; in addition, it has positive influence on personal, familial, societal, and country's development $[3,4]$. Different scholars have used several measurements for women empowerment such as economic, sociocultural, legal, political, and psychological measures [5-7].

In Demographic and Health Survey (DHS), attitude towards wife beating is one of the indicators of women empowerment $[8,9]$. Few previous studies have reported an association between attitude towards wife beating and child health [7, 10-13]. For instance, studies in Benin [7] and SSA have shown that there is a positive influence of women empowerment on child feeding practices and nutritional status [11]. Another study in SSA by Yaya et al. showed that empowering women can reduce childhood malnutrition [12]. Women empowerment's influence on the uptake of child health services is also documented in Zimbabwe [14] and other low- and middle-income countries [13].

Evidence in SSA reported that child's characteristics such as child's age, size, and sex, maternal and/or household socioeconomic status, hygiene, and sanitation condition, and geographic related factors were associated with childhood diarrhea [15-18]. Meanwhile, one study in Indonesia has shown an association between attitude towards wife beating and childhood diarrhea [19]. However, the association between attitude towards wife beating and childhood diarrhea is not well studied in SSA. Therefore, the present study aimed to examine the association between attitude towards wife beating and diarrhea among under-five children in 25 countries in SSA.

\section{Methods}

2.1. Data Source. We extracted DHS data from 25 countries in SSA for analysis in this study (Table 1). DHS are nationally representative surveys aimed to collect data for monitoring demographic and several health indicators including women empowerment and childhood diarrhea [20]. These surveys are carried out in low- and middle-income countries with the financial and technical support of United States Aids for International Development (USAID) and International Child Fund (ICF), respectively [21].

DHS applied a stratified two-stage cluster sampling technique. In the first stage, Enumeration Areas (EA) were selected systematically from the sampling frame prepared from the recent national population census. Then, in the second stage, fixed numbers of households (usually 25-30 households) were selected using Probability Proportional to Size (PPS) technique [22]. Based on our inclusion criteria (country with DHS between 2010 and 2019, availability of dataset that had the variables of interest), we included 25 countries. We used the Individual Recode (IR) file for the analysis and the data are freely available at https:// dhsprogram.com/data/available-datasets.cfm. We followed the guidelines of Strengthening of Observational Studies in Epidemiology (STROBE) during preparation of this manuscript [23].

As shown in Figure 1, a total of 213,151 living children under age 5 were included in the surveys. Of them, 153,864 had diarrhea in the 2 weeks preceding the survey, and all are included for analysis of this study (Figure 1).

\subsection{Study Variables}

2.2.1. Outcome Variable. The outcome variable of the study was childhood diarrhea. The number of living children under age of 5 with diarrhea in the 2 weeks preceding the survey was included $[24,25]$. According to WHO, diarrhea is defined as the passage of three or more loose or liquid stools per day [26]. For this study, we included only under-five children of married women. 


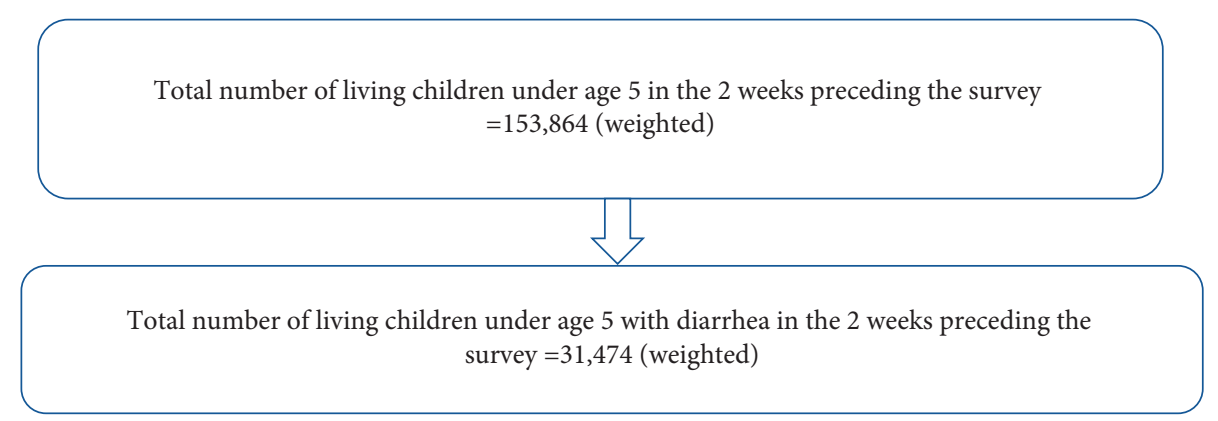

FIGURE 1: Schematic representation of sampling procedures: evidence from 25 SSA countries DHSs.

2.2.2. Independent Variable. The independent variable of interest for this study was attitude towards wife beating. In DHS, married women aged 15-49 who disagree/not justify for all of five wife beating reasons, burning food, arguing with husband, going out without telling husband, neglecting the children, and refusing to have sexual intercourse with husband, are considered as empowered. However, if the married women agree/justify for at least one of abovementioned wife beating reasons, they are not considered as empowered. Based on this concept, we categorized/coded them as 1 if the married women disagreed/not justified wife beating for all five reasons, and we coded them as 0 if the women agreed/justified for at least one of the five abovementioned wife beating reasons $[8,27-30]$.

2.2.3. Control Variables. Based on previous studies [15-18], we considered eleven control variables that influence the outcome variable such as age in years [11, 15-48], women's educational level (no formal education, primary school, secondary school, and higher), husband educational level (no formal education, primary school, secondary school, and higher), women's occupation (not working, professional/ technical/managerial, agricultural, manual, and others), wealth index (poorest, poorer, middle, richer, and richest), media exposure (no and yes), place of residence (urban and rural), parity ( $\leq 2,3-4$, and $5+$ ), decision making (no and yes), barriers to healthcare access (no and yes), and religion (Christian, Muslim, and others).

2.3. Statistical Analyses. Using Stata version 14 software, the analysis was carried out using the following steps. First, descriptive analyses, such as frequencies of the dependent variable, independent variable, and control variables, were done and presented using table and graphs. Then, bivariate logistic regression analyses were conducted to select candidate control variables at $p$ value less than or equal to 0.15 $(p \leq 0.15)$. We considered this to include many confounders $[31,32]$. Then, multicollinearity test was conducted using Variance Inflation Factor (VIF) to check whether there was collinearity among the independent and/or control variables and we discovered that there was no evidence of collinearity (mean VIF $=1.90$, Min VIF $=1.00$, Max VIF = 3.77). Finally, multivariate logistic regression analysis was conducted by including all control variables that were selected at the bivariate analysis, along with the independent variable to check the association between wife beating attitude (disagreed/not justified for wife beating) and childhood diarrhea. The model fitness was checked using Hosmer-Lemeshow and confirmed that the model was fit $(p=0.8735)$. The results were presented using crude odd ratio (COR) and adjusted odd ratio (AOR), at 95\% confidence interval (CI). To take care of the complex nature DHS's data, we used the "svyset" command during analysis, and all three design elements, that is, weight, cluster, and strata, were taken into consideration.

2.4. Ethical Clearance. We used publicly available secondary data for analysis of this study (available at: https:// dhsprogram.com/data/available-datasets.cfm). Since ethical procedures are the responsibility of institutions that funded, commissioned, and managed the surveys, further ethical clearance was not required. ICF international approved that all the DHS surveys follow the US Department of Health and Human Services rules, for respecting of human subject's rights. For more details related to ethical issues, readers can visit http://goo.gl/ny8T6X.

\section{Results}

3.1. Sociodemographic Characteristics. In total, 153,864 under-five children of married women/care givers were involved in this analysis. Regarding respondents, from this total, about $7.9 \%$ were within the age groups of $15-19$ years, while $35.3 \%$ of the respondents were rural residents. More than onequarter $(27.5 \%)$ of the respondents and one-fifth $(21.1 \%)$ of their husbands had no formal education. Regarding wife beating attitude, approximately 34.6\% married women did not decide by themselves or together with their husband on at least one of the three decision-making parameters: their own health, to purchase large household expenses, and to visit families/relatives. $28.6 \%$ of married women justified wife beating practice by their husband for at least one of the five wife beating reasons: going out without telling their husband, arguing with their husband, neglecting children, burning foods, and refusing to have sex with their husband. However, $71.4 \%$ of married women did not justify/accept wife beating in any of the five wife beating reasons.

3.2. Prevalence of Disagreement with Wife Beating. The pooled result shows that about $71.4 \%$ (95\% CI; $69.3 \%-$ $73.4 \%$ ) of married women in the 25 countries in SSA 


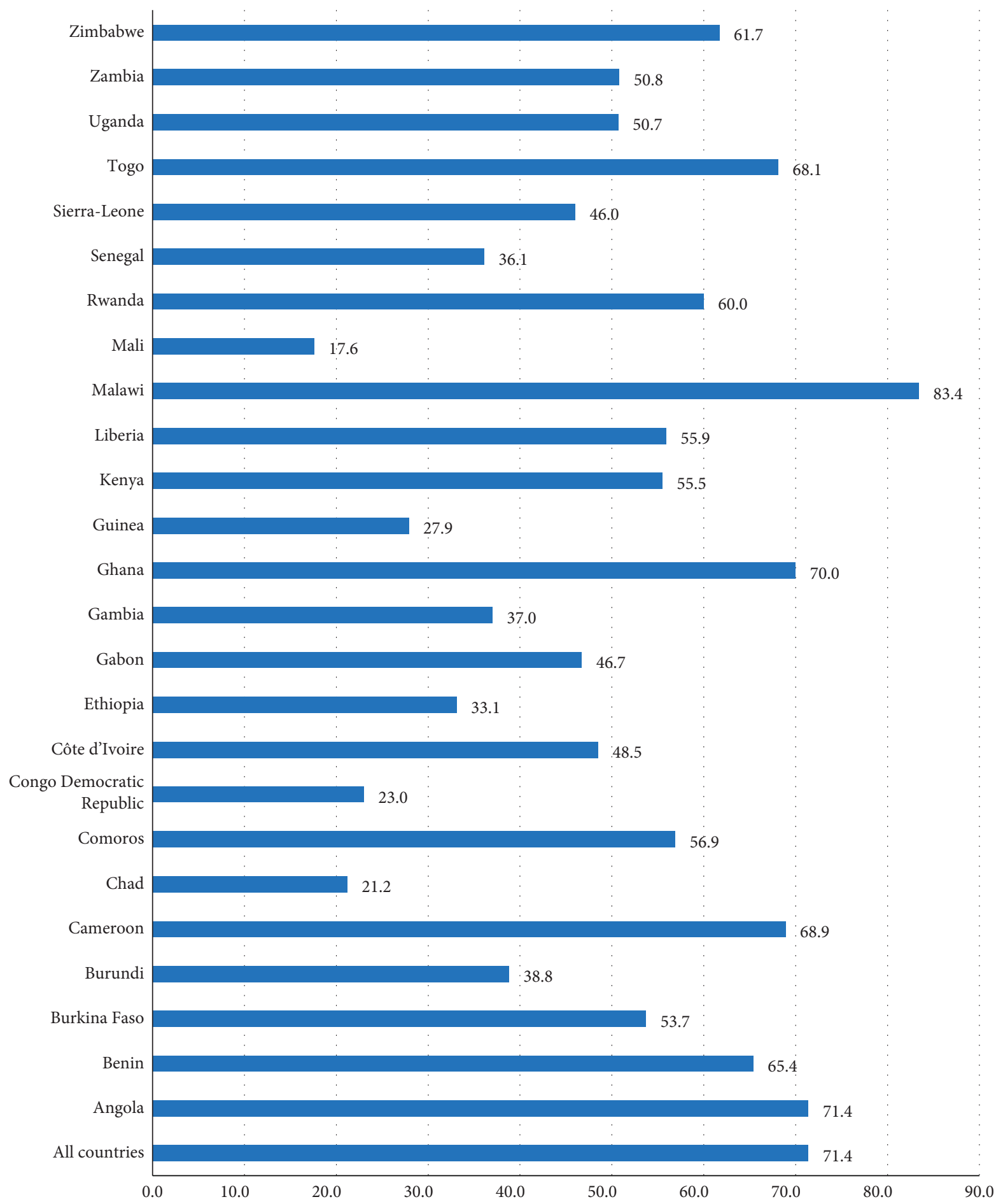

FIGURE 2: Prevalence of disagreement with wife beating among married women of children under five in SSA.

disagreed with all of the five wife beating reasons, with the highest (83.4\%) and lowest (17.7\%) prevalence in Malawi and Mali, respectively (Figure 2).

3.3. Distribution of Prevalence of Childhood Diarrhea across Explanatory/Control Variables. As shown in Table 2, prevalence of childhood diarrhea varied across subpopulations of explanatory variables. For instance, prevalence of childhood diarrhea among children from married women who were empowered was $18.3 \%$, while it was $25.6 \%$ among married women who were not empowered. Similarly, childhood diarrhea varied across married women's age. For instance, about $25 \%$ of under-five children from married women within the age groups of 20-24 years had diarrhea, while about $11.9 \%$ of under-five years children had diarrhea among married women 
TABLE 2: Frequency distribution of respondents and distribution of childhood diarrhea cross explanatory variables: evidence from 25 SSA countries.

\begin{tabular}{|c|c|c|c|}
\hline \multirow[t]{2}{*}{ Variables } & \multirow{2}{*}{$\begin{array}{c}\text { Frequency } \\
\text { (weighted \%) }\end{array}$} & \multicolumn{2}{|c|}{$\begin{array}{l}\text { Childhood diarrhea } \\
\text { (weighted \%) }\end{array}$} \\
\hline & & No & Yes \\
\hline \multicolumn{4}{|l|}{ Are women empowered } \\
\hline No & $77,421(29.41)$ & 74.39 & 25.61 \\
\hline Yes & $71,149(70.59)$ & 81.69 & 18.31 \\
\hline \multicolumn{4}{|l|}{ Age in years } \\
\hline $15-19$ & $9,115(7.86)$ & 79.96 & 20.04 \\
\hline $20-24$ & $33,137(19.88)$ & 75.04 & 24.96 \\
\hline $25-29$ & $41,127(21.60)$ & 78.3 & 21.70 \\
\hline $30-34$ & $32,813(16.88)$ & 80.78 & 19.22 \\
\hline $35-39$ & $23,473(14.56)$ & 84.59 & 15.41 \\
\hline $40-44$ & $11,579(11.73)$ & 82.28 & 17.72 \\
\hline $45-49$ & $3,661(7.51)$ & 88.12 & 11.88 \\
\hline \multicolumn{4}{|l|}{ Women's educational level } \\
\hline No formal education & $67,559(27.57)$ & 79.72 & 20.28 \\
\hline Primary school & $52,631(39.40)$ & 78.45 & 21.55 \\
\hline Secondary school & $30,359(29.58)$ & 79.94 & 20.06 \\
\hline Higher & $4,349(3.45)$ & 87.23 & 12.77 \\
\hline \multicolumn{4}{|l|}{ Husband educational level } \\
\hline No formal education & $59,036(21.44)$ & 83.10 & 16.90 \\
\hline Primary school & $40,825(27.08)$ & 76.98 & 23.02 \\
\hline Secondary school & $39,195(44.61)$ & 79.34 & 20.66 \\
\hline Higher & $8,888(6.87)$ & 79.90 & 20.10 \\
\hline \multicolumn{4}{|l|}{ Women's occupation } \\
\hline Not working & $41,443(25.79)$ & 81.75 & 18.25 \\
\hline Professional/technical/managerial & $4,611(4.64)$ & 81.52 & 18.48 \\
\hline Agricultural & $56,360(30.40)$ & 79.28 & 20.72 \\
\hline Manual & $10,342(3.16)$ & 77.10 & 22.90 \\
\hline Others & $35,783(36.02)$ & 78.15 & 21.85 \\
\hline \multicolumn{4}{|l|}{ Wealth index } \\
\hline Poorest & $38,027(18.36)$ & 80.66 & 19.34 \\
\hline Poorer & $33,570(21.96)$ & 78.06 & 21.94 \\
\hline Middle & $30,749(21.52)$ & 78.98 & 21.02 \\
\hline Richer & $27,703(20.03)$ & 79.34 & 20.66 \\
\hline Richest & $24,856(18.14)$ & 81.11 & 18.89 \\
\hline \multicolumn{4}{|l|}{ Place of residence } \\
\hline Urban & $46,125(63.85)$ & 79.68 & 20.32 \\
\hline Rural & $108,780(36.15)$ & 79.30 & 20.70 \\
\hline \multicolumn{4}{|l|}{ Parity } \\
\hline$\leq 2$ & $54,446(31.71)$ & 77.43 & 22.57 \\
\hline $3-4$ & $47,247(31.54)$ & 80.72 & 19.28 \\
\hline $5+$ & $53,212(36.75)$ & 80.28 & 19.72 \\
\hline \multicolumn{4}{|l|}{ Decision making } \\
\hline No & $89,153(35.44)$ & 77.35 & 22.65 \\
\hline Yes & $59,375(64.56)$ & 80.75 & 19.25 \\
\hline \multicolumn{4}{|l|}{ Barriers to healthcare access } \\
\hline No & $46,486(30.33)$ & 80.07 & 19.93 \\
\hline Yes & $95,713(69.67)$ & 79.32 & 20.68 \\
\hline \multicolumn{4}{|l|}{ Religion } \\
\hline Christian & $90,493(93.22)$ & 79.47 & 20.53 \\
\hline Muslim & $56,720(0.31)$ & 54.35 & 45.65 \\
\hline Others & $7,565(6.48)$ & 81.74 & 18.26 \\
\hline \multicolumn{4}{|l|}{ Media exposure } \\
\hline No & $73,283(29.25)$ & 81.51 & 18.49 \\
\hline Yes & $81,272(70.75)$ & 78.73 & 21.27 \\
\hline
\end{tabular}

who were within 44-49 years of age. Prevalence of childhood diarrhea also varied based on religious beliefs. For instance, approximately $45.7 \%$ of under-five children had diarrhea, but the prevalence was lowered to about $18.3 \%$ and $20.5 \%$ among under-five children who belonged to other religions and Christianity, respectively (Table 2). 


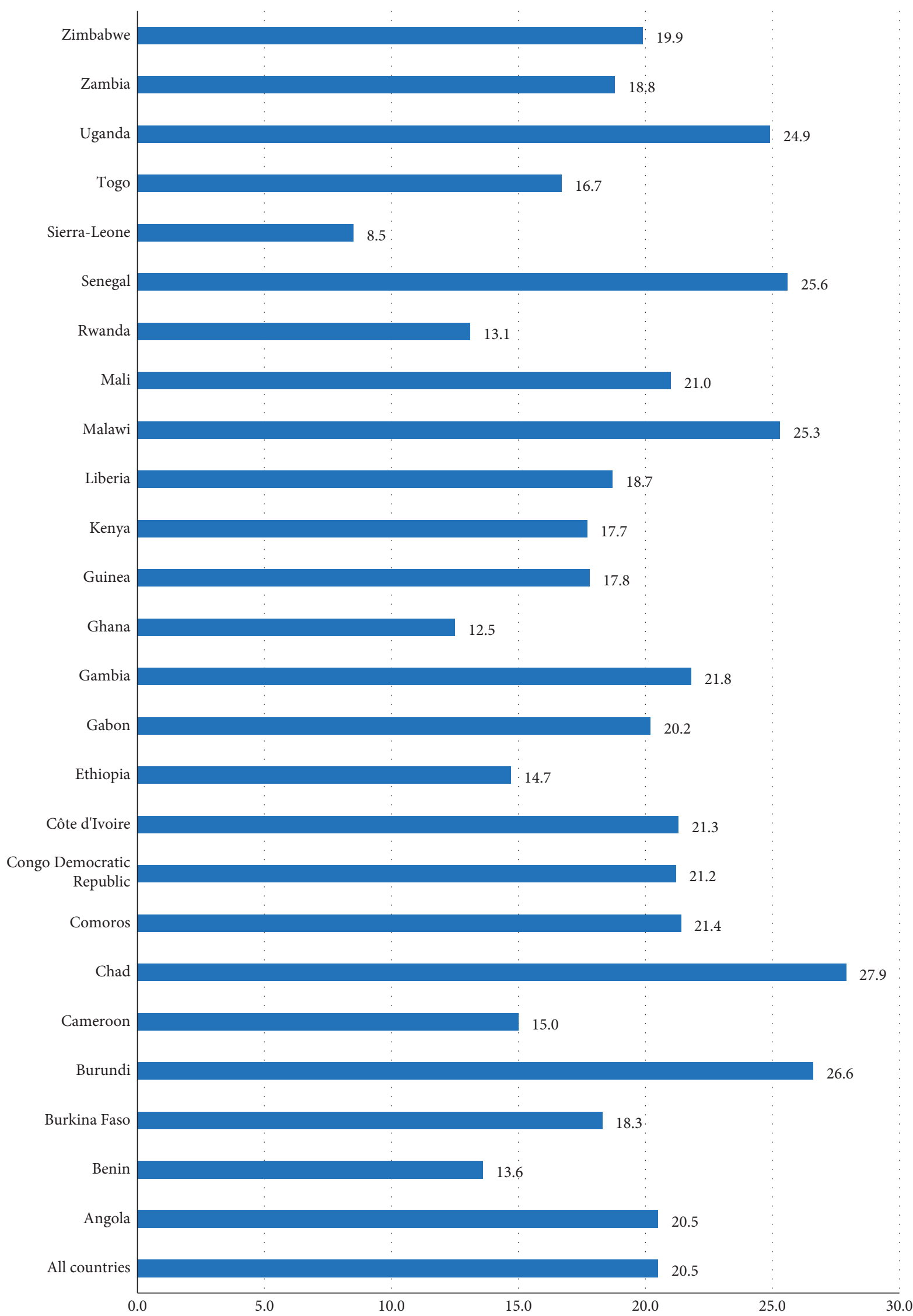

FIGURE 3: Prevalence of diarrhea among children under five of married women in sub-Saharan Africa. 
TABle 3: Association between wife beating attitude and childhood diarrhea among married women: evidence from 25 SSA countries.

\begin{tabular}{|c|c|c|c|c|}
\hline Variables & cOR $(95 \% \mathrm{CI})$ & $p$ value & aOR $(95 \% \mathrm{CI})$ & $p$ value \\
\hline \multicolumn{5}{|l|}{ Women are empowered } \\
\hline No & Ref & & Ref & \\
\hline Yes & $0.65(0.53-0.78)$ & $<0.001$ & $0.66(0.54-0.80)$ & 0.001 \\
\hline \multicolumn{5}{|l|}{ Control variables } \\
\hline \multicolumn{5}{|l|}{ Age in years } \\
\hline $15-19$ & Ref & & Ref & \\
\hline $20-24$ & $1.32(0.97-1.80)$ & 0.074 & $1.21(0.89-1.64)$ & 0.218 \\
\hline $25-29$ & $1.10(0.80-1.51)$ & 0.530 & $0.86(0.61-1.23)$ & 0.434 \\
\hline $30-34$ & $0.94(0.64-1.40)$ & 0.793 & $0.68(0.44-1.04)$ & 0.076 \\
\hline $35-39$ & $0.72(0.49-1.07)$ & 0.111 & $0.48(0.31-0.74)$ & 0.001 \\
\hline $40-44$ & $0.85(0.55-1.33)$ & 0.498 & $0.57(0.35-0.93)$ & 0.024 \\
\hline $45-49$ & $0.53(0.25-1.12)$ & 0.097 & $0.35(0.16-0.79)$ & 0.012 \\
\hline \multicolumn{5}{|l|}{ Women's educational level } \\
\hline No formal education & Ref & & & \\
\hline Primary school & $1.07(0.85-1.35)$ & 0.511 & NA & NA \\
\hline Secondary school & $0.98(0.78-1.23)$ & 0.902 & NA & NA \\
\hline Higher & $0.57(0.21-1.57)$ & 0.282 & NA & NA \\
\hline \multicolumn{5}{|l|}{ Husband educational level } \\
\hline No formal education & Ref & & Ref & \\
\hline Primary school & $1.47(1.13-1.89)$ & 0.003 & $1.36(1.05-1.77)$ & 0.020 \\
\hline Secondary school & $1.28(1.03-1.57)$ & 0.020 & $1.19(0.95-1.49)$ & 0.118 \\
\hline Higher & $1.23(0.76-1.99)$ & 0.385 & $1.33(0.80-2.22)$ & 0.257 \\
\hline \multicolumn{5}{|l|}{ Women's occupation } \\
\hline Not working & Ref & & Ref & \\
\hline Professional/technical/managerial & $1.01(0.60-1.70)$ & 0.955 & $1.28(0.77-2.13)$ & 0.324 \\
\hline Agricultural & $1.17(0.92-1.47)$ & 0.182 & $1.22(0.94-1.60)$ & 0.129 \\
\hline Manual & $1.33(0.80-2.21)$ & 0.270 & $1.35(0.81-2.25)$ & 0.237 \\
\hline Others & $1.25(0.96-1.63)$ & 0.096 & $1.30(1.00-1.70)$ & 0.046 \\
\hline \multicolumn{5}{|l|}{ Wealth index } \\
\hline Poorest & Ref & & & \\
\hline Poorer & $1.17(0.91-1.49)$ & 0.201 & NA & NA \\
\hline Middle & $1.10(0.86-1.43)$ & 0.419 & NA & NA \\
\hline Richer & $1.08(0.78-1.49)$ & 0.613 & NA & NA \\
\hline Richest & $0.97(0.69-1.34)$ & 0.861 & NA & NA \\
\hline \multicolumn{5}{|l|}{ Media exposure } \\
\hline No & Ref & & Ref & \\
\hline Yes & $1.19(0.98-1.43)$ & 0.065 & $1.25(0.99-1.57)$ & 0.057 \\
\hline \multicolumn{5}{|l|}{ Place of residence } \\
\hline Urban & Ref & & & \\
\hline Rural & $1.02(0.83-1.25)$ & 0.821 & NA & NA \\
\hline \multicolumn{5}{|l|}{ Parity } \\
\hline$\leq 2$ & Ref & & Ref & \\
\hline $3-4$ & $1.18(0.98-1.43)$ & 0.075 & $1.36(1.09-1.70)$ & 0.006 \\
\hline $5+$ & $0.97(0.75-1.25)$ & 0.829 & $1.56(1.14-2.12)$ & 0.005 \\
\hline \multicolumn{5}{|l|}{ Decision making } \\
\hline No & Ref & & Ref & \\
\hline Yes & $0.81(0.66-1.00)$ & 0.052 & $0.83(0.68-1.01)$ & 0.077 \\
\hline \multicolumn{5}{|l|}{ Barriers to healthcare access } \\
\hline No & Ref & & & \\
\hline Yes & $1.04(0.84-1.29)$ & 0.663 & NA & NA \\
\hline \multicolumn{5}{|l|}{ Religion } \\
\hline Christian & Ref & & Ref & \\
\hline Muslim & $3.25(1.37-7.67)$ & 0.007 & $3.56(1.44-8.83)$ & 0.006 \\
\hline Others & $0.86(0.58-1.26)$ & 0.458 & $0.89(0.60-1.32)$ & 0.578 \\
\hline
\end{tabular}

cOR: crude odd ratio, aOR: adjusted odd ratio, Ref: reference, and NA: not included variable due to being not significant at bivariate logistic regression. Bold values denote statistical significance at the $\mathrm{p}<0.05$ level.

3.4. Prevalence of Childhood Diarrhea. As shown in Figure 3, the pooled results from the 25 sub-Saharan African countries show that about $20.5 \%$ (95\% CI; $18.7 \%-22.3 \%)$ of under-five years of age children from married women had diarrhea. Prevalence of childhood diarrhea varied across studied countries. The study shows that the highest prevalence of childhood diarrhea was observed in Chad (27.9\%), Burundi (26.6\%), Liberia (26\%), Senegal (25.6\%), Malawi 
(25.3\%), and Uganda (24.9\%), respectively. On the other hand, lowest childhood diarrhea was observed in SierraLeone (8.5\%), Ghana (12.5\%), Rwanda (13.1\%), Benin (13.6\%), and Ethiopia (14.8\%), respectively (Figure 3).

3.5. Association between Women's Attitude towards Wife Beating and Childhood Diarrhea. Table 3 shows the association between attitude towards wife beating and childhood diarrhea. More specifically, the study shows lower odds of diarrhea among under-five children of married women who disagreed with wife beating ( $\mathrm{aOR}=0.6695 \% \mathrm{CI}$; 0.54-0.80) compared to under-five children of married women who agreed with wife beating. The study also shows lower odds of diarrhea among under-five children of married women within the age groups of $35-39$ years $(0.48,95 \%$ CI; $0.31-0.74), 40-44$ years $(\mathrm{aOR}=0.57,95 \% \mathrm{CI} ; 0.35-0.93)$, and $45-49$ years $(\mathrm{aOR}=0.35,95 \% \mathrm{CI} ; 0.16-0.79)$ compared to under-five children of married women within the age groups of 15-19 years.

Moreover, the study shows higher odds of diarrhea among under-five children of married women whose husband had attended primary school $(\mathrm{aOR}=1.36,95 \% \mathrm{CI}$; 1.05-1.77) compared to under-five children of married women whose husbands did not attend formal education. In this study, we observed higher odds of diarrhea among under-five children of married women who ever gave birth to 3-4 children $(\mathrm{aOR}=1.36,95 \% \mathrm{CI} ; 1.09-1.70)$ and $5+$ children $(\mathrm{aOR}=1.56,95 \% \mathrm{CI} ; 1.14-2.12)$ compared to under-five children of married women who ever gave birth to less than or equal to two children. Finally, we found higher odds of diarrhea among under-five children of married women who belonged to Islam $(\mathrm{aOR}=3.56,95 \% \mathrm{CI}$; 1.44-8.83) compared to under-five children of married women who belonged to the Christianity.

\section{Discussion}

To the best of our knowledge, this is the first study to examine the association between married women's attitude towards wife beating and childhood diarrhea in SSA. The pooled results from the 25 sub-Saharan African countries show that about $71.4 \%$ of married women were empowered (disagreed with wife beating), and about $20.5 \%$ of under-five children of married women had diarrhea. This finding is higher compared to previous studies in Ethiopia (14.9\%) [33] India (9\%) [34] and SSA (16\%) [16]. Higher prevalence of childhood diarrhea among children of married women in the present study could be due to variations in the methodology we used including the target population $[35,36]$. We only included married women because maternal and child health services are more challenging among married women $[35,36]$. This might be for the reason that domestic violence and poor decision-making power [35, 36], financial dependency on men, and the need of husband's consent for access and utilization of healthcare services [35].

In this study, we found lower odds of diarrhea among under-five children of married women who disagreed with wife beating compared to under-five children of married women who agreed with wife beating. Comparable findings were reported in prior studies in Indonesia [19]. Lower odds of diarrhea among under-five children of married women who disagreed/not justified for wife beating could be due to higher decision-making power [37], better socioeconomic status $[38,39]$, health seeking behavior, and utilization of child health services, such as immunization $[13,40]$ and child feeding practices $[7,11,12,41]$. Evidence shows that women who disagree/not justified wife beating usually utilize maternal health services, such as antenatal care, health facility delivery, and postnatal care [36, 42]. Better care of children and health seeking behavior for child health services are seen among women who usually utilize maternal health services and visit health institutions [43].

We found that the odds of diarrhea were lower among under-five children of older married women compared to under-five children of adolescent married women as documented in SSA [16] and Pernambuco, Brazil [44]. This could be because younger women might be inexperienced in care of children including feeding of their children compared to older women $[16,44,45]$. Again, this experience might help the women to have more knowledge and demonstrate their knowledge in prevention of diarrhea [16].

In contrast with a previous study in Ethiopia [46], the present study shows that there were higher odds of diarrhea among under-five children of married women whose husband attended primary school compared to under-five children of married women whose husband had no formal education. This may need further studies to know the mechanism why higher odds of childhood diarrhea are seen among women with educated husband.

This study shows that the odds of diarrhea were higher among under-five children of married women with higher paritycompared to under-five children of married women with lower parity. This could be due to the effect of high parity itself and their relations with short birth interval deplete maternal nutrition and child survival for infectious diseases [47]. The physical and caloric demands, mixed with physical and caloric stress life in repeated pregnancy result in depletion of maternal nutritional status [48]. The other justification could be children from high parity women usually become nutritionally poor and vulnerable for infection because of smaller parental food security and/or competition among family members or siblings for limited resources [48].

Moreover, the present study showed the association between religious beliefs and childhood diarrhea [34, 49, 50]. This finding is comparable with previous studies in India [34, 49], Kenya, Nigeria, and Niger [50] that showed the association between religion and healthcare seeking behavior for childhood diarrhea. This could be linked with the women's religious beliefs/perceptions as well as religious authorities' prohibition to modern treatment seeking from health facilities $[49,50]$. More specifically, we found higher odds of diarrhea among under-five children of married women who belonged to Islamic religion compared to under-five children of married women who professed to be Christian. A previous study in India showed that the odds of childhood diarrhea were $18 \%$ higher among children who 
belonged to Islamic religion compared to Hindu [34]. Previous study in SSA [51] showed that child mortality was also significantly higher among Muslim women compared to non-Muslim women. Meanwhile, in Nigeria, in the study on women with at least one live birth, $43 \%$ of Muslims had at least one child death and 29\% among non-Muslims [51]. This could be related to utilization of maternal and child health services [51] and lower years of schooling among Muslim women compared to non-Muslim women [51]. A prior study in SSA showed the large difference in years of schooling from 9.2 years to 3.2 years between non-Muslim and Muslim women, respectively [51]. Not only among Muslim women has evidence showed that generally the majority of Muslim adults in SSA lack basic educational attainment [52, 53], but also different prior studies in India [34], Bangladesh [54], and different parts of Ethiopia [55, 56] documented that better childcare, feeding, and hygiene practice are associated with women education.

The other possible reason for higher odds of childhood diarrhea among children of Muslim women could be linkage between nonacceptance and poor utilization of vaccination, such as Rota virus [57]. However, WHO delivered a report on the joint view of Islamic religious academics, saying that animal-derived medical products, including vaccines, that undergo a transformation are considered clean [58]. Not all of the Islamic faith considers vaccines to be halal or allowable under Islamic Shariah Law [57]. In situations where vaccine is considered haram (banned), children might not get immunization services and still vulnerable for life threatening disease and need working with religious leaders especially where vaccines are strictly prohibited [57].

4.1. Strengths and Limitations of the Study. Using nationally representative and large sample size, examining attitude towards wife beating and childhood diarrhea in 25 countries in SSA is a major strength of the paper. However, the study has the following limitations. First, the cross-sectional nature of DHS data might not allow inferring cause-effect relationships. Second, since the data were self-reported, recall bias might affect the findings. Third, since we included only married women, the findings might not be applicable to all reproductive age $[11,15-48]$ women and finally, because of exclusion criteria few countries in SSA were not included and the findings might not be applicable to all sub-Saharan African countries.

\section{Conclusion}

The findings from the pooled results show that a large proportion of married women (71.4\%) disagreed with all the five reasons for wife beating and one-fifth of under-five children had diarrhea. Childhood diarrhea varied from a highest prevalence in Chad (27.9\%) to a lowest prevalence in Sierra-Leone (8.5\%). We found lower odds of childhood diarrhea among married women who disagreed with wife beating compared to children of married women who agreed with wife beating. Moreover, the study shows that women's age, husband's education, parity, and religion were associated with diarrhea among under-five children.

Therefore, in order to improve prevalence ofdiarrhea among children under five in SSA, the national government in each country and other stakeholders who are concerned for child health need to work on women empowerment. The interventions may be implemented through multidimensional mechanisms including education, and economy and other strategies, such as increasing awareness about domestic violence and their reproductive and human rights, especially for young women. Furthermore, strengthening of family planning services or birth spacing and working closely with religious leaders also are important to reduce childhood diarrhea.

\section{Data Availability}

Data for this study were sourced from Demographic and Health Surveys (DHS) and are available here http:// dhsprogram.com/data/available-datasets.cfm.

\section{Ethical Approval}

Ethical approval was not required for this study since the data are secondary and are available in the public domain. More details regarding DHS data and ethical standards are available at http://goo.gl/ny8T6X.

\section{Consent}

Not applicable.

\section{Conflicts of Interest}

The authors declare that they have no conflicts of interest.

\section{Authors' Contributions}

SY and BZ designed the study, collected the data, performed the first analysis, and drafted the manuscript. MP, BOA, EKA, and AS critically revised the manuscript for its intellectual content. SY had final responsibility to submit for publication. All the authors approved the final version of the manuscript for publication.

\section{Acknowledgments}

The authors thank the MEASURE DHS Project for their support and for free access to the original data.

\section{References}

[1] WHO Children, "Improving survival and wellbeing," 2021, https://ww.who.int/news-room/fact-sheets.detail/childrenreducing-mortality.

[2] UNICEF Child Health, "Diarrheal disease," 2021, https://data. unicef.org/topic/child-health/diarrhoeal-disease/.

[3] MOWCY, UNICEF Ethiopia, and SPRI, Gender Equality, Women's Empowerment and Child Wellbeing in Ethiopia, UNICEF, New York, NY, USA, 2019. 
[4] USAID, "Gender Equality and Women's Empowerment in Ethiopia," 2018, https://www.usaid.gov/ethiopia/genderequality-andwomens-empowerment.

[5] A. Malhotra, S. R. Schuler, and C. Boender, "Measuring women's empowerment as a variable in international development," 2002, https://siteresources.worldbank.org/ INTEMPOWERMENT/Resources/486312-1095970750368/ 5297631095970803335/malhotra.pdf.

[6] F. W. Bayissa, J. Smits, and R. Ruben, "The multidimensional nature of women's empowerment: beyond the economic approach," Journal of International Development, vol. 30, no. 4, pp. 661-690, 2018.

[7] H. Alaofe, M. Zhu, J. Burney, R. Naylor, and T. Douglas, "Association between women's empowerment and maternal and child nutrition in kalalé district of Northern Benin," Food and Nutrition Bulletin, vol. 38, no. 3, pp. 302-318, 2017.

[8] S. Kishor and L. Subaiya, "Understanding women's empowerment: a comparative analysis of demographic and health surveys (DHS) data," https://dhsprogram.com/ publications/publication-cr20-comparativereports.cfm DHS comparative reports No. 20, Macro International Inc, Calverton, MD, USA, 2008, https://dhsprogram.com/ publications/publication-cr20-comparativereports.cfm DHS comparative reports No. 20.

[9] T. N. Croft, A. M. J. Marshall, and C. K. Allen, Guide to DHS Statistics, ICF, Rockville, MD, USA, 2018.

[10] S. K. Abreha, S. Z. Walelign, and Y. A. Zereyesus, "Associations between women's empowerment and children's health status in Ethiopia," PLoS One, vol. 15, no. 7, Article ID e0235825, 2020.

[11] M. Na, L. Jennings, S. A. Talegawkar, and S. Ahmed, "Association between women's empowerment and infant and child feeding practices in sub-saharan Africa: an analysis of demographic and health surveys," Public Health Nutrition, vol. 18, no. 17, pp. 3155-3165, 2015.

[12] S. Yaya, E. K. Odusina, O. A. Uthman, and G. Bishwajit, "What does women's empowerment have to do with malnutrition in Sub-Saharan Africa? Evidence from demographic and health surveys from 30 countries," Global Health Research and Policy, vol. 5, no. 1, p. 1, 2020.

[13] P. Pratley, "Associations between quantitative measures of women's empowerment and access to care and health status for mothers and their children: a systematic review of evidence from the developing world," Social Science \& Medicine, vol. 169, no. 1, pp. 119-131, 2016.

[14] N. Ndaimani, M. Mhlanga, and V. Dube-Mawerewere, "The association between women's empowerment and uptake of child health services: a demographic and health survey based synthesis," ICF, Rockville, MD, USA, DHS Working Paper No. 139, 2018.

[15] A. Alebel, C. Tesema, B. Temesgen, A. Gebrie, P. Petrucka, and G. D. Kibret, "Prevalence and determinants of diarrhea among under-five children in Ethiopia: a systematic review and meta-analysis," PLoS One, vol. 13, Article ID e0199684, 2018.

[16] S. T. Adedokun and S. Yaya, "Childhood morbidity and its determinants: evidence from 31 countries in sub-Saharan Africa," BMJ Global Health, vol. 5, Article ID e003109, 2020.

[17] A. Getachew, T. Guadu, A. Tadie et al., "Diarrhea prevalence and sociodemographic factors among under-five children in rural areas of North Gondar Zone, Northwest Ethiopia," International Journal of Pediatrics, vol. 20188 pages, Article ID 6031594, 2018.
[18] GBD 2017 Diarrhoeal Disease Collaborators, "Quantifying risks and interventions that have affected the burden of diarrhoea among children younger than 5 years: an analysis of the Global Burden of Disease Study 2017," The Lancet Infectious Diseases, vol. 20, no. 1, pp. 37-59, 2020.

[19] E. Astutik, F. Efendi, S. K. Sebayang, S. Hadisuyatmana, E. M. Mh, and H. Kuswanto, “Association between women's empowerment and diarhea in children under two years in Indonesia," Children and Youth Services Review, vol. 113, Article ID 105004, 2020.

[20] DHS Program, "Methodology: survey type," 2021, https:// dhsprogram.com/methodology/survey-Types/dHs.cfm.

[21] The DHS Program, "Quality information to plan, monitor and improve population, health, and nutrition programs," 2021, https://dhsprogram.com/.

[22] DHS Program, "Guide to DHS statistics. Analyzing DHS data," 2021, https://dhsprogram.com/data/Guide-to-DHSStatistics/Analyzing_DHS_Data.htm.

[23] E. von Elm, D. G. Altman, M. Egger, S. J. Pocock, P. C. Gøtzsche, and J. P. Vandenbroucke, "The strengthening the reporting of observational studies in epidemiology (STROBE) statement: guidelines for reporting observational studies," International Journal of Surgery, vol. 12, no. 12, pp. 1495-1499, 2014.

[24] S. O. Rutstein, S. Staveteig, R. Winter, and J. Yourkavitch, "Urban child poverty, health, and survival in low- and middleincome countries," DHS Comparative Reports No. 40, ICF International, Rockville, MD, USA, 2021, https://www. dhsprogram.com/publications/publication-CR40-ComparativeReports.cfm DHS Comparative Reports No. 40.

[25] WHO and UNICEF, Ending Preventable Child Deaths from Pneumonia and Diarrhoea by 2025: The Integrated Global Action Plan for Pneumonia and Diarrhoea (GAPPD), WHO, Geneva, Switzerland, 2013, http://www.who.int/maternal_ child_adolescent/documents/global_action_plan_pneumonia_ diarrhoea/en/.

[26] WHO, Diarrhoeal Disease, World Health Organization, Geneva, Switzerland, 2018, https://www.who.int/news-room/ fact-sheets/detail/diarrhoeal-disease.

[27] N. B. Ebrahim and M. S. Atteraya, "Women's decisionmaking autonomy and their attitude towards wife-beating: findings from the 2011 Ethiopia's demographic and health survey," Journal of Immigrant and Minority Health, vol. 20, no. 3, pp. 603-611, 2018.

[28] K. A. Oyediran, "Explaining trends and patterns in attitudes towards wife-beating among women in Nigeria: Analysis of 2003, 2008, and 2013. Demographic and health survey data," Genus, vol. 72, no. 11, 2016.

[29] A. A. Mengistu, "Socioeconomic and demographic factors influencing women's attitude toward wife beating in Ethiopia," Journal of Interpersonal Violence, vol. 34, no. 15, pp. 3290-3316, 2019.

[30] E. Gurmu and S. Endale, "Wife beating refusal among women of reproductive age in urban and rural Ethiopia," BMC International Health and Human Rights, vol. 17, no. 1, p. 6, 2017.

[31] R. L. Wasserstein, A. L. Schirm, and N. A. Lazar, "Moving to a world beyond "p," The American Statistician, vol. 73, no. sup1, pp. 1-19, 2019.

[32] Z. Bursac, C. H. Gauss, D. K. Williams, and D. W. Hosmer, "Purposeful selection of variables in logistic regression," Source Code for Biology and Medicine, vol. 3, p. 17, 2008.

[33] D. G. Kasye, N. H. Garoma, and M. A. Kassa, "Assessment of the prevalence of diarrheal disease under-five children serbo 
town, Jimma zone south west Ethiopia," Clinics in Mother and Child Health, vol. 15, no. 1, p. 281, 2018.

[34] P. Paul, "Socio-demographic and environmental factors associated with diarrhoeal disease among children under five in India," BMC Public Health, vol. 20, p. 1886, 2020.

[35] WHO, Accessing and Utilization of Healthcare Services for Married Women Especially in Developing Countries Including SSA Countries are Difficult WHO. Addressing the Challenge of Women's Health in Africa. A Summary of the Report of the Commission on Women's Health in the African Region, WHO Regional Office for Africa, Geneva, Switzerland, 2012.

[36] F. N. Tiruneh, K.-Y. Chuang, and Y.-C. Chuang, "Women's autonomy and maternal healthcare service utilization in Ethiopia," BMC Health Services Research, vol. 17, no. 1, p. 718, 2017.

[37] Y. D. Wado, "Women's autonomy and reproductive healthcare-seeking behavior in Ethiopia," ICF International, Rockville, MD, USA, 2013, https://dhsprogram.com/pubs/ pdf/WP91/WP91.pdf DHS Working Papers No. 91.

[38] M. W. Pambe, B. Gnoumou, and I. Kabore, "Relationship between women's socioeconomic status and empowerment in Burkina Faso: a focus on participation in decision-making and experience of domestic violence," ICF International, Rockville, MD, USA, 2013, https://dhsprogram.com/pubs/pdf/ WP99/WP99.pdf DHS Working Papers No. 90.

[39] Z. T. Dimbuene, J. Amo-Adjei, D. Amugsi, J. Mumah, C. O. Izugbara, and D. Beguy, "Women's education and utilization of maternal health services in Africa: a multicountry and socioeconomic status analysis," Journal of Biosocial Science, vol. 6, pp. 1-24, 2017.

[40] S. Thorpe, K. VanderEnde, C. Peters, L. Bardin, and K. M. Yount, “The influence of women's empowerment on child immunization coverage in low, lower-middle, and upper-middle income countries: a systematic review of the literature," Maternal and Child Health Journal, vol. 20, no. 1, pp. 172-186, 2016.

[41] K. Cunningham, M. Ruel, E. Ferguson, and R. Uauy, "Women's empowerment and child nutritional status in south Asia: a synthesis of the literature," Maternal and Child $\mathrm{Nu}$ trition, vol. 11, no. 1, pp. 1-19, 2015.

[42] M. N. Khan and M. M. Islam, "Women's attitude towards wife-beating and its relationship with reproductive healthcare seeking behavior: a countrywide population survey in Bangladesh," PLoS One, vol. 13, no. 6, Article ID e0198833, 2018.

[43] M. Azage and D. Haile, "Factors affecting healthcare service utilization of mothers who had children with diarrhea in Ethiopia: evidence from a population based national survey," Rural and Remote Health, vol. 15, no. 4, p. 3493, 2015.

[44] M. J. d. O. B. Vasconcelos, A. Rissin, J. N. Figueiroa, P. I. C. d. Lira, and M. Batista Filho, "Fatores associados à diarreia em menores de cinco anos, no estado de Pernambuco, segundo inquéritos realizados em 1997 e 2006," Revista de Saúde Pública, vol. 52, p. 48, 2018.

[45] J. Picot, D. Hartwell, P. Harris, D. Mendes, A. J. Clegg, and A. Takeda, "The effectiveness of interventions to treat severe acute malnutrition in young children: a systematic review," Health Technology Assessment (Winchester, England), vol. 16, no. 19, pp. 1-316, 2012.

[46] K. Takele, T. Zewotir, and D. Ndanguza, "Risk factors of morbidity among children under age five in Ethiopia," $B M C$ Public Health, vol. 19, p. 942, 2019.

[47] B. Girma and Y. Berhane, "Children who were vaccinated, breast fed and from low parity mothers live longer: a community based case-control study in Jimma," Ethiopia. BMC Public Health, vol. 11, p. 197, 2011.

[48] E. Sonneveldt, W. D. Plosky, and J. Stover, "Linking high parity and maternal and child mortality: what is the impact of lower health services coverage among higher order births?" BMC Public Health, vol. 13, no. Suppl 3, p. S7, 2013.

[49] R. Bawankule, S. Shetye, A. Singh, A. Singh, and K. Kumar, "Epidemiological investigation and management of bloody diarrhea among children in India," PLoS One, vol. 14, no. 9, Article ID e0222208, 2019.

[50] K. J. Bedford and A. B. Sharkey, "Local barriers and solutions to improve care-seeking for childhood pneumonia, diarrhoea and malaria in Kenya, Nigeria and Niger: a qualitative study," PLoS One, vol. 9, no. 6, Article ID e100038, 2014.

[51] F. W. Charles and K. Bietsch, Religion and Reproductive Behavior in Sub-Saharan Africa. DHS Analytical Studies No. 48, ICF International, Rockville, MD, USA, 2015.

[52] Pew Research Center, Religion and Education Around the World, Pew research center, Washington, DC, USA, 2016, http://www.pewforum.org/2016/12/13/religion-and-educationaround-the-world/.

[53] O. Mfum-Mensah, "Education and communities at. The "margins": the contradictions of western education for islamic communities in sub-saharan Africa," in BCES Conference BooksVol. 15, Bulgarian Comparative Education Society, Sofia, Bulgaria, 2017.

[54] A. R. Sarker, M. Sultana, R. A. Mahumud, and N. Sheikh, "Van Der Meer R, Morton A. Prevalence and health care-seeking behavior for childhood diarrheal disease in Bangladesh," Glob Pediatr Health, vol. 3, pp. 1-12, 2016.

[55] B. Melese, W. Paulos, F. H. Astawesegn, and T. B. Gelgelu, "Prevalence of diarrheal diseases and associated factors among under-five children in Dale District, Sidama zone, southern Ethiopia: a cross-sectional study," BMC Public Health, vol. 19, no. 1, p. 1235, 2019.

[56] T. Sinmegn Mihrete, G. Asres Alemie, and A. Shimeka Teferra, "Determinants of childhood diarrhea among underfive children in Benishangul Gumuz regional state, North West Ethiopia," BMC Pediatrics, vol. 14, no. 1, p. 102, 2014.

[57] R. S. Padmawati, A. Heywood, M. N. Sitaresmi et al., "Religious and community leaders' acceptance of rotavirus vaccine introduction in Yogyakarta, Indonesia: a qualitative study," BMC Public Health, vol. 19, p. 368, 2019.

[58] World Health Organization, "Rotavirus vaccines: WHO position paper-January 2013," Vaccins Antirotavirus: Note de Synthèse de l'OMS, vol. 88, no. 5, pp. 49-64, 2013, https://apps. who.int/iris/handle/10665/242024. 